Floyd, K. B. 1983. Chronology of appearance and habitat partitioning by stream larval fishes. Masters Thesis, Western Kentucky University, Bowling Green, KY.

Kindschi, G. A., R. D. Hoyt, and G. J. Overmann. 1979. Some aspects of the ecology of larval fishes in Rough River Lake, KY. Pages 139166. In Hoyt, R. D., ed., Proceedings of the third symposium on larval fish. Western Kentucky University, Bowling Green, KY.
Verheijen, F. J. 1958. The mechanisms of the trapping effect of artificial light sources upon animals. Arch. Neerland de Zool. 13:1-107.

Keith B. Floyd, William H. Courtenay, Robert D. Hoyt, Ogden College of Science, Technology, and Health, Western Kentucky University, Bowling Green, Kentucky 42101

\title{
A Portable, Diver-Operated, Underwater Pumping Device
}

Pumping devices have been used to sample a variety of aquatic organisms and life stages, particularly when such collection is unobtainable via conventional sampling gear. Recently, Evans (1981) used an on-board centrifugal pump to sample zooplankton in southeastern Lake Michigan, and Nigro and Ney (1982) utilized a similar apparatus to collect alewife eggs from the bottom of a reservoir. Dorr et al. (1981) also used a centrifugal pump to collect lake trout eggs from interstices of a southeastern Lake Michigan reef. The pumping system was equipped with an upstream trap to minimize damage to eggs. Stauffer (1981) compared efficiencies of three pumping systems for collection of lake trout eggs and fry from a Lake Superior reef and concluded that a diverassisted, on-board pumping system was more efficient than a remotely operated one. All these pumping systems required major effort to implement and were expensive. Basic requirements included: a medium- to highoutput electric or gasoline driven pump with intake hoses of sufficient length to reach bottom; a $110 \mathrm{~V}$ or $220 \mathrm{~V} \mathrm{AC}$ power supply for electric pumps; and surface support personnel to operate the pump and tend divers.

A pumping device is described herein that is compact, portable, and manually operated by two divers. The system can provide a flow of 60-120 L/minute (about 15-30 gpm) with moderate physical effort. Also, the diaphragm pumping mechanism and relatively large internal dimensions of the pump and fittings in- flict minimal damage to fragile objects. With this device, Dorr et al. (1981) collected epibenthic algae and zooplankton, sediment and organic detritus, periphyton scraped from substrates, invertebrates (fingernail clams, snails, Hydra, crayfish), fish eggs (alewife, Alosa pseudoharengus; lake trout, Salvelinus namaycush), and young-of-the-year sculpins (Cottus spp.).

Two WHALE "Gusher 10" hand-operated diaphragm pumps (Munster Simms Engineering Ltd., Bangor, N. Ireland) were mounted in tandem on an adustable hardwood frame (painted with epoxy paint) that could be knelt on by the diver to stablize the device during pumping (Fig. 1 and 2). A 3-m-long flexible plastic hose $3.8 \mathrm{~cm}(1.5 \mathrm{in})$ in diameter was attached to the common intake port. The end of the intake hose was fitted with a standard vacuum cleaner end to which could be attached a variety of fittings to sample flat or uneven surfaces and crevices. The bulk of the pump plumbing consisted of standard-sized PVC fittings, clear plastic tubing (tygon), and hose clamps. The common exhaust port, which could be watched by the diver while he pumped, could be fitted with a variety of receptacles such as a plankton bucket or net of varying size or mesh. The entire apparatus weighed about $6.8 \mathrm{~kg}$ ( $15 \mathrm{lb}$ ), could be easily handled by one person, and was weighted to be slightly negatively bouyant. Total cost was about $\$ 280$, but much of this was incurred by the choice of pumps; less expensive diaphragm 


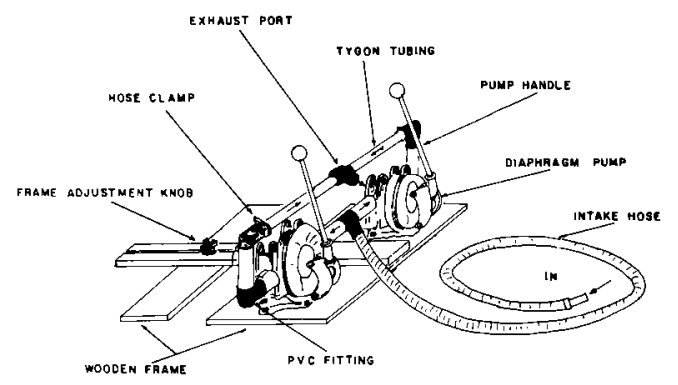

Fig. 1. Schematic of pumping device showing two diaphragm pumps mounted in tandem on an adjustable wooden frame, PVC fittings and clear plastic tubing (tygon), and intake and outlet.

pumps are available that would reduce the cost to about $\$ 125$. Construction materials in addition to the pumps are available at most hardware or plumbing supply stores. The pumps can be purchased from most marine hardware suppliers.

The two diaphragm pumps are operated in opposite phases of their cycle to facilitate continuous suction and uniform flow of water. The device is operated by two divers (Fig. 2) and with moderate effort one diver can pump for 15-30 minutes while the other diver directs the intake hose and probes the substrate. It has proved to be durable and easy to transport above or below water. Additional information regarding construction and application to sampling needs can be obtained from the authors.

\section{Acknowledgments}

We thank David J. Jude and Frank J. Tesar for reviewing the manuscript, and Dennis K. Mounsey, who prepared the illustration. The research which stimulated construction of this device was sponsored by Michigan Sea Grant, Ann Arbor, MI.

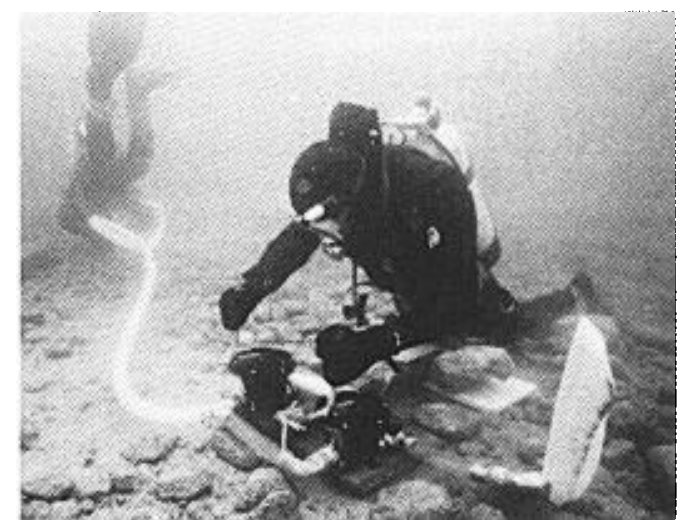

Fig. 2. SCUBA divers using pumping device to collect benthic flora and fauna at $10 \mathrm{~m}$ in eastern Lake Michigan.

\section{References Cited}

Dorr III, J. A., D. V. O'Connor, N. R. Foster, and D. J. Jude. 1981. Substrate conditions and abundance of lake trout eggs in a traditional spawning area in Lake Michigan. N. Amer. J. Fish. Mgt. 1:165-172.

Dorr III, J. A., D. J. Jude, G. R. Heufelder, S. A. Klinger, G. E. Noguchi, T. L. Rutecki, and P. J. Schneeberger. 1981. Preliminary investigation of spawning habitat conditions and reproduction of lake trout in eastern Lake Michigan near Port Sheldon, Michigan. Michigan Sea Grant Pub. MICHU-81-213, Ann Arbor, MI.

Evans, M. S. 1981. Distribution of zooplankton populations within and adjacent to a thermal plume. Can. J. Fish. Aquat. Sci. 38:441-448.

Nigro, A. A., and J. J. Ney. 1982. Reproduction and early life accommodations of landlocked alewives to a southern range extension. Trans. Am. Fish. Soc. 111:559-569.

Stauffer, T. M. 1981. Collecting gear for lake trout eggs and fry. Prog. Fish-Cult. 43:186-193.

Loren E. Flath and John A. Dorr III,

Great Lakes Research Division,

The University of Michigan,

Ann Arbor, Michigan. 